\title{
Análise de parâmetros na otimização de vigas de concreto utilizando o algoritmo
}

\section{Colônia de Vagalumes}

\author{
Parameter analysis in the optimization of concrete beams using the algorithm Colony of Fireflies \\ Análisis de parámetros en la optimización de vigas de hormigón utilizando el algoritmo Colonia de \\ Luciérnagas
}

Recebido: 17/01/2022 | Revisado: 22/01/2022 | Aceito: 26/01/2022 | Publicado: 28/01/2022

Eliakim Alcântara de Sousa Fontes
ORCID: https://orcid.org/0000-0003-1721-709X
Instituto Federal de Educação, Ciência e Tecnologia de Sergipe, Brasil
E-mail: eliakimalcantara9@gmail.com
Mila Crisna Matos da Silva
ORCID: https://orcid.org/0000-0002-5283-2293
Faculdade Estácio de Belém, Brasil
E-mail: milacrisna @gmail.com
Leonardo Teles Rodrigues
Faculdade Estácio de Belém, Brasil
ORCID: https://orcid.org/000-0003-04583
E-mail: leoteles.rodrigues@ hotmail.com
Guilherme Orion Rodrigues Mendonça
ORCID: https://orcid.org/0000-0002-3121-6854
Pontifícia Universidade Católica de Campinas, Brasil
E-mail: guilherme.orion.rm@gmail.com
Camila Costa Câmara de Souza Mello
ORCID: https://orcid.org/0000-0002-4483-8468
Universidade Federal do Rio Grande do Norte, Brasil
E-mail camilacostacs@yahoo.com.br

\begin{abstract}
Resumo
Existem na literatura muitos caminhos para se otimizar estruturas, entretanto o uso de algoritmos bioinspirados ainda é pouco explorado. Diante desse contexto, esse artigo busca verificar, utilizando o algoritmo bioinspirado Colônia de Vagalumes, os parâmetros para a otimização de três variáveis do processo construtivo de uma viga através da minoração de suas funções-objetivo, dando, ao final, seu custo de produção por metro linear. Foram analisados diversos valores de parâmetros para se chegar àqueles que melhor se adequassem ao objetivo proposto. Os resultados obtidos mostraram evidências da robustez do algoritmo, atingindo convergência para um valor muito próximo do ideal depois de poucas iterações. Fica clara sua relevância e o seu potencial de uso para elementos construtivos muito mais robustos.
\end{abstract}

Palavras-chave: Otimização; Algoritmos bioinspirados; Colônia de vagalumes; Vigas.

\begin{abstract}
There are many ways in the literature to optimize structures using a wide range of algorithms, however the use of bioinspired algorithms for structures is still little explored. Given this context, this article demand to verify, using the bioinspired algorithm Colony of Fireflies, the parameters for the optimization of three variables of the construction process of a beam through the reduction of its objective functions, giving, in the end, its production cost per linear meter. Several parameter values were analyzed to arrive at those that best suited the proposed objective. The results obtained showed evidence of the robustness of the algorithm, reaching convergence to a value very close to the ideal after few iterations. Its relevance and potential use for much more robust construction elements is clear.
\end{abstract}

Keywords: Optimization; Bioinspired algorithms; Colony of fireflies; Beam.

\section{Resumen}

Hay muchas formas en la literatura para optimizar estructuras, sin embargo, el uso de algoritmos bioinspirados aún está poco explorado. En ese contexto, este artículo busca verificar, utilizando el algoritmo bioinspirado Colônia de Vagalumes, los parámetros para la optimización de tres variables del proceso de construcción de una viga a través de la reducción de sus funciones objetivo, dando, al final, su costo de producción. por metro. Se analizaron varios valores de parámetros para llegar a aquellos que más se adecuaban al objetivo propuesto. Los resultados obtenidos mostraron evidencia de la robustez del algoritmo, alcanzando convergencia a un valor muy cercano al ideal después de pocas iteraciones. Su relevancia y potencial uso para elementos constructivos mucho más robustos es clara.

Palabras clave: Optimización; Algoritmos bioinspirados; Colonia de luciérnagas; Vigas. 


\section{Introdução}

\subsection{Otimização}

À medida que se busca atender as crescentes necessidades do mercado e da sociedade em relação à produção mais rápida e melhor de bens e serviços, os processos de otimização se fazem cada vez mais necessários. Esses processos já vêm sendo empregados em várias áreas, como em projetos de redes de abastecimento de água, na dosagem de materiais, no gerenciamento de itinerários de linhas de transporte, bem como na otimização de projetos de estruturas (Olivieri, 2004).

A otimização é um processo fundamental e inerente à realidade em que se vive atualmente. A função clássica dos engenheiros - de todas as subáreas da Engenharia - é encontrar soluções que possuam melhor desempenho técnico aliado ao menor custo, ou seja, otimizadas. Sendo assim, pode-se dizer que engenharia e otimização são indissociáveis.

Além de desempenho técnico e menor custo, a minoração dos impactos ambientais gerados pelos processos humanos tem sido uma preocupação crescente no século XXI. Sendo assim, uma solução ótima precisa atender a esses três requisitos: técnica correta, baixo custo e menor impacto ao meio ambiente. Um bom profissional nunca se dará por satisfeito até alcançar o máximo de melhoria que lhe for possível em seu produto ou serviço.

Otimização pode ser definida também como um subconjunto da Pesquisa Operacional, método bastante difundido nas Engenharias Mecânica e de Produção, que proporciona aos profissionais que têm acesso ao seu escopo a obtenção de um procedimento organizado e consistente que o auxiliará na difícil tarefa de gestão de recursos. Fazendo uso do método científico, a otimização encontra uma solução ótima ou um conjunto delas para uma determinada função ou problema. Ela pode ser utilizada para melhorar um processo ou encontrar a solução para determinado problema.

Soluções ótimas são aquelas nas quais, a partir de um modelo, você encontra o melhor resultado para o problema em questão, utilizando a menor quantidade de recursos possível e respeitando as condições de contorno às quais ela está sujeita. Todavia, nem sempre é viável alcançar o ótimo. Geralmente, encontrar uma solução ótima significa encontrar a melhor solução possível dentro de um conjunto de soluções exatas ou inexatas.

A utilização de modelos otimizados tende a apoiar a tomada de decisões com maior embasamento e chance de satisfazer à questão vital do confronto entre a melhor solução técnica aliada à melhor solução economicamente viável. Malagoli (2016) dá alguns exemplos de problemas práticos de otimização. Dentre eles, estão:

- Determinar o melhor projeto possível para um circuito elétrico de um edifício;

- Determinar o melhor ajuste possível para os controles de um processo industrial;

- Gerar o menor custo de fabricação de um determinado produto;

- Estabelecer rotas de mínimo custo para entrega de produtos a clientes.

\subsection{Bioinspiração}

Desde a sua origem, a espécie humana tem se inspirado na natureza à sua volta, em especial certos comportamentos animais, para desenvolvimento de novas técnicas utilizadas para resolver problemas considerados complexos. Seja para encontrar alimento ou abrigo, ou confeccionar utensílios que os ajudassem a sobreviver num ambiente adverso, os humanos aprenderam muito cedo que observando seres de outras espécies e imitando alguns dos seus comportamentos, a sobrevivência se tornaria mais fácil.

Com a evolução das sociedades humanas, soluções advindas da inspiração pelo natural começaram a ser utilizadas em diversas áreas da ciência. Atualmente, a utilização de algoritmos bioinspirados se difundiu bastante na busca de soluções para os mais diversos problemas de engenharia e computação. Isso porque estes algoritmos conseguem lidar com a busca de 
mínimos e máximos de funções, mesmo que estas possuam características extremamente não-lineares, dificilmente resultando em apenas um resultado para y em função de x, ou que sejam de difícil solução analítica (Remes et al., 2014).

O termo bioinspiração refere-se a uma classe de meta-heurísticas, métodos inteligentes flexíveis, pois possuem uma estrutura com componentes genéricos que são adaptados ao problema que se quer resolver (Arroyo, 2002), que emprega metáforas de modelos biológicos na programação de ferramentas computacionais para a resolução de problemas complexos, como exemplifica a Figura 1.

Figura 1: Exemplo de bioinspiração (Alves, 2016).

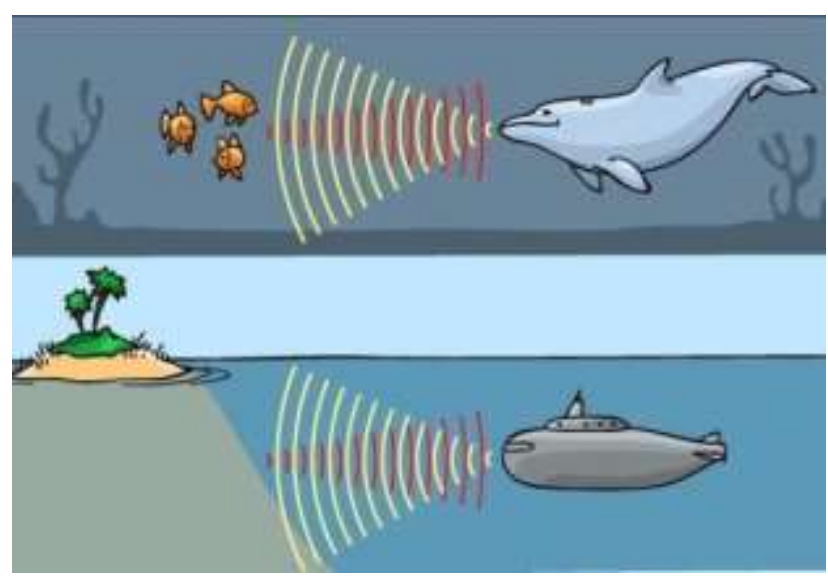

Fonte: Alves (2016).

Essa aplicação se faz possível porque é de conhecimento do meio científico que a seleção natural, teoria esboçada por Charles Darwin entre 1832 e 1844, selecionou ao longo de milhares de anos os processos biológicos mais eficientes. Dessa forma, houve uma convergência para soluções ótimas ou próximas delas, de modo que apenas estas conseguissem perpetuar seus genes.

O número de aplicações em que os $\mathrm{ABs}$ podem ser utilizados vem crescendo a passos largos nos últimos anos. Segundo Barbosa (2017), a área de pesquisa da Ciência da Computação e afins que utiliza esses algoritmos também é conhecida como Computação Natural. Ela procura compreender os padrões encontrados na natureza, para aplicá-los no desenvolvimento de ferramentas computacionais e assim resolver problemas complexos ou aperfeiçoar sistemas já existentes, sem necessariamente capturar todos os detalhes e, quando necessário, utilizando simplificações. O uso da bioinspiração implica redução de esforço computacional, evitando que as máquinas sejam sobrecarregadas. Além disso, o cálculo de um número gigantesco de probabilidades duraria um tempo elevado, às vezes impraticável de ser esperado por quem necessita de desempenho.

Para representar esse problema associado ao tempo, pode-se tomar como exemplo a classe de problemas provenientes do Problema do Caixeiro, que, segundo Rebouças (2016), tem sido objeto de estudo de vários pesquisadores desde o início do século XIX, e continua um forte ramo de pesquisa até hoje.

"Suponha que um caixeiro viajante tenha de visitar $\mathrm{n}$ cidades diferentes, iniciando e encerrando sua viagem na primeira cidade. Suponha, também, que não importa a ordem com que as cidades são visitadas e que de cada uma delas podese ir diretamente a qualquer outra. O problema do caixeiro viajante consiste em descobrir a rota que torna mínima a viagem total".

A resolução do problema proposto se dá através da equação 1: 
Onde:

n é o número de cidades;

Divide-se por 2 por causa da simetria no sistema, ou seja, a saída e a chegada ocorrem na mesma posição dentro da cidade.

Para $\mathrm{n}=3$, há apenas uma possibilidade. Aumentando para $\mathrm{n}=4$, há 3 trajetórias possíveis. Quando se aumenta $\mathrm{o}$ número de cidades para 6 , obtém-se 60 ciclos distintos. Ao aumentar esse valor para 15, o número de rotas alcança 43.589.145.600. Se esse número for aumentado ainda mais - para 20, por exemplo - a quantidade de viagens chega a aproximadamente $6,08 * 10^{16}$ alternativas. Utilizando um computador muito potente e capaz de realizar 1 bilhão de adições por segundo, seriam necessários aproximadamente 73 anos para resolver tal problemática. A Figura 2 representa a curva gráfica originada por esse problema.

Figura 2: Representação gráfica do Problema do caixeiro viajante.

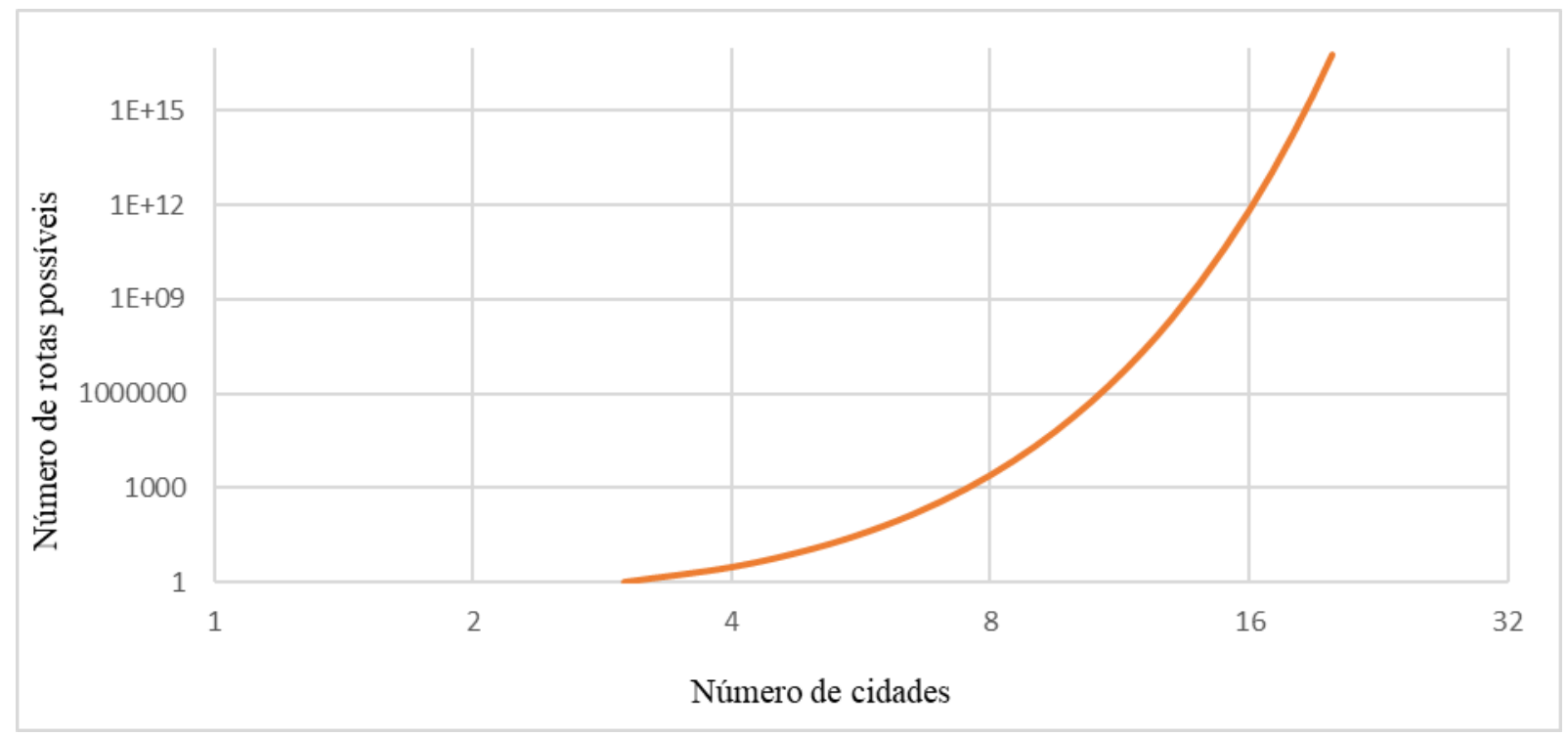

Fonte: Autores (2022).

\subsection{Bioinspiração na engenharia de estruturas}

Como já foi dito anteriormente, a bioinspiração acarreta em redução do esforço computacional, evitando que as máquinas sejam sobrecarregadas. Na Engenharia de Estruturas, esse fator se faz presente, sobretudo, no que diz respeito ao desenvolvimento de projetos estruturais. Ao serem desenvolvidos por métodos convencionais, seus cálculos giram em torno de um elevado número de variáveis de projeto, o que os torna complexos, demorados de serem realizados e, segundo Silva (2015), sem garantias de que a solução obtida seja a melhor tanto do ponto vista estrutural quanto econômico.

Segundo a CBIC - Câmara Brasileira da Indústria da Construção (2020), a construção civil cresceu 1,6\% em 2019, após 5 anos negativados. Já em 2020, quando continuava dando sinais da sua esperada ascensão pelo comportamento senoidal histórico do setor, foi atingido por outra crise: a pandemia causada pelo novo corona vírus (COVID-19). 
O grande problema enfrentado dessa vez foi a alta dos preços de materiais essenciais para a construção civil. De acordo com dados da Fundação Getúlio Vargas, a alta nos preços dos materiais em 2020 foi de 19,60\%, a maior do período pós-real; alguns insumos chegaram a registrar aumentos superiores a 50\% no período (CBIC, 2021). Assim, o mercado da construção civil se vê numa situação de obrigatoriedade de busca por alternativas do jeito de construir, o que arremete ainda mais para a importância do aproveitamento de todo material empregado (Fernandes et al., 2017).

Lopez e Miguel (2013) discorrem, ainda, que o uso de técnicas de otimização, especialmente as técnicas bioinspiradas, beneficiam não só o mercado, mas também os novos profissionais da área, já que o emprego de tais ferramentas diminuem a necessidade de anos de experiência como projetista de estrutural, aumentando sua competitividade no mercado da área.

Nesse contexto, o objetivo desse artigo é otimizar três vigas de concreto armado moldado in loco através do Algoritmo Bioinspirado Colônia de Vagalumes, encontrando a solução ótima para altura e armadura delas e seu custo mínimo e, além disso, apresentar a convergência da otimização das três vigas e o custo para a execução de 1 metro linear de cada uma delas.

\section{Metodologia}

Trata-se de um estudo de caso sobre a utilização de três vigas de concreto moldado por meio do Algoritmo Bioinspirado Colônia de Vagalumes com abordagens qualitativas e quantitativas (Estrela, 2018; Pereira et al., 2018). Este estudo teve como referência o algoritmo utilizado por Fernandes et al. (2017) e seu estudo foi baseado no trabalho de Xavier Junior et al. (2020), em que aplicaram o algoritmo Particle Swarm Optimization (Örkcü et al., 2015) em uma estação pluviométrica de Campina Grande (PB).

Vagalumes são insetos noturnos famosos por sua característica bioluminescente, isto é, produzem luz naturalmente para certos fins. Segundo Fister (2013), esses fins são basicamente comunicação e atração para potenciais parceiros, predação e alerta para predadores. Baseando-se no comportamento social desses insetos para a reprodução, Yang (2008) propôs o ACV. Essa característica é vista em algumas espécies de vagalumes, onde a taxa de intermitência e a intensidade de cada flash é parte essencial do mecanismo de atração do sexo oposto para acasalamento (Moreira, 2015).

$\mathrm{O}$ autor desse algoritmo definiu três regras simplificadoras em relação ao fenômeno de bioluminescência dos vagalumes para a construção do ACV. As duas primeiras regras se mantêm constantes em relação às duas edições (a primeira em 2008 e a segunda em 2010) do seu livro Nature-inspired metaheuristic algorithms e preconizam o seguinte:

1) Todos os vagalumes possuem o mesmo sexo, ou seja, qualquer vagalume poderá atrair ou ser atraído;

2) A atratividade de um vagalume é diretamente proporcional ao brilho que ele emite e inversamente proporcional à sua distância em relação a outro vagalume.

Em relação à terceira regra, a edição de 2008 preconiza que:

3) O brilho emitido é determinado em comparação com seu valor na função objetivo, ou seja, quanto melhor avaliado maior será o seu brilho.

Enquanto que a edição 2010 estabelece que:

3) Caso não haja nenhum vagalume mais brilhante que os demais, eles se moverão aleatoriamente.

É importante ressaltar três importantes quesitos nos quais o Algoritmo Colônia de Vagalumes se baseia: e intensidade do brilho, atratividade e distância entre os vagalumes. Ao enfatizar esses quesitos e dando especial atenção à regra dois imposta por Yang $(2008 ; 2010)$, tem-se o proposto por Cirino et al. (2013), ao discorrer que a intensidade de emissão de luz de um vagalume é proporcional à função objetivo, porém a intensidade de luz que outro vagalume percebe decai em função da distância entre os dois. 
Em relação à intensidade da luz emitida/percebida, tem-se a equação 2, descrita por Rastgou \& Moshtagh (2016):

$$
I(r)=I 0 e^{-\gamma r^{2}}
$$

Onde:

Io a intensidade emitida;

$\gamma$ o parâmetro de absorção de luz pelo meio;

$r$ a distância entres os vagalumes i e j;

Enquanto que o fator de atratividade é regido pela equação 3:

$$
\xi=\xi o e^{-Y T^{2}}
$$

Onde:

乌̌o é a atratividade para distância igual a 0 .

Portanto, a movimentação de um vagalume menos atraente para outro mais atraente é representada pela equação 4.

$$
x i=x i+\xi o e^{-r^{2}} i j(x j+x i)+\alpha\left(\operatorname{rand}-\frac{1}{2}\right)
$$

Onde:

$x i$ é o vagalume mais brilhante;

$x j$ é o vagalume menos brilhante;

๔ é a inserção de aleatoriedade.

Para que se torne viável a utilização do ACV, é preciso informar cinco parâmetros iniciais, a saber, número de variáveis de projeto, número da população de vagalumes, número de gerações, fator de atratividade $(\xi)$ e fator de aleatoriedade $(\alpha)$.

O pseudolinguagem algorítmica do ACV pode ser descrita como (Yang, 2016):

Função objetivo $\mathrm{f}(\mathrm{x}), x=\left(x 1_{x, \ldots, x d}\right)^{T}$

Definir os parâmetros inicias (NP, D, $\beta \mathrm{o}, \alpha$ e MG)

Para $\mathbf{i}=1$ até o número máximo de gerações faça

Calcular a intensidade da luz (Ii) para xi proporcionalmente a $j(x i)$

Para $j=1$ até o número de vagalumes

Calcular o fato de atratividade (Equação $\mathrm{n}^{\circ}$ )

Mover j para i (Equação n ${ }^{\circ}$ )

Verificar se os vagalumes estão dentro dos limites

\section{Fim-para}

\section{Fim-para}


Pós-processamento e visualização dos resultados.

\section{Fim}

A partir do algoritmo bioinspirado Colônia de Vagalumes, com utilização de sub-rotinas já desenvolvidas por Fernandes et al. (2017) e empregando a ferramenta computacional GNU Octave ${ }^{\circledR}$, foram processados alguns exemplos gerais da Engenharia Civil.

O objetivo desse processo foi verificar a otimização de três variáveis do processo construtivo de uma viga, a saber, sua altura útil, sua armadura à tração e sua armadura à compressão e estabelecer o custo por metro linear de viga através da equação 12. Essas variáveis, no algoritmo, são chamadas respectivamente de $x_{1}, x_{2}$ e $x_{\mathrm{g}}$. Entretanto, nesse trabalho, elas serão chamas de $d, A s$ e $A s^{*}$.

$$
\text { Custo }=b w *\left(d+d^{v}\right) * C 1+\left(A s+A s^{0}\right) * \rho * C 2+\left(b w+2 *\left(d+d^{v}\right)\right) * C 3 \quad \text { Eq. (2) }
$$

Onde:

bw é a largura da alma da viga;

d'é distância entre o eixo da armadura de compressão e a face mais próxima do elemento;

$\rho$ é a massa específica do aço;

C1 é o custo do concreto por $\mathrm{m}^{3}$;

C2 é o custo do aço por kg;

C3 é o custo da forma por $\mathrm{m}^{2}$

Os valores de concreto, aço e forma foram obtidos através da tabela de preços do Orçamento de Obras de Sergipe (ORSE, 2021) mais recente (fevereiro/2021), conforme indicados a seguir:

Concreto $-\mathrm{R} \$ 457,65 / \mathrm{m}^{3}$

Aço - R\$ 10,04 / kg

Forma $-\mathrm{R} \$ 26,69 / \mathrm{m}^{2}$

Com base nos resultados obtidos através do Octave ${ }^{\circledR}$, foram criadas planilhas na ferramenta Microsoft Excel, que forneceram gráficos através dos quais foi possível examinar de forma objetiva as informações apresentadas.

A partir disso, foi realizada uma análise da convergência da otimização de três vigas através do método bioinspirado de colônia de vagalumes.

\subsection{Gnu Octave}

Concebido originalmente para ser para ser um software complementar para um livro de graduação sobre projeto de reatores químicos, o Octave ${ }^{\circledR}$ é, hoje, uma linguagem de alto nível, principalmente destinada a cálculos numéricos. Para cumprimento de sua destinação precípua, seus desenvolvedores optaram por construir uma ferramenta flexível e adaptável em oposição ao uso de ferramentas altamente especializadas. Essa característica possibilita que o software seja usado para resolver problemas realistas em muitas outras áreas além de problemas de projeto de reatores químicos, no meio acadêmico e de pesquisa e em aplicações comerciais. 
Um dos pontos positivos do Octave® é que ele é facilmente extensível e personalizável por meio de funções definidas pelo usuário escritas na sua própria linguagem ou usando módulos carregados dinamicamente escritos em $\mathrm{C}++, \mathrm{C}$, Fortran ou outras linguagens. Além disso, é um software livremente redistribuível, ou seja, há a possibilidade de redistribuí-lo e/ou modificá-lo.

Por fim, a Free Software Foundation incentiva a livre utilização do software e encoraja a contribuição dos seus usuários através da inserção de funções adicionais e o relato dos novos usos da ferramenta em seus trabalhos. Isso permite um crescimento exponencial de funções (sub-rotinas) pré-programadas e suas consequentes aplicações.

A máquina utilizada foi um Notebook com o processador Intel Core I5 e 8GB de memória RAM, enquanto que, em relação à ferramenta computacional definida, foi utilizada a versão 6.2.0-w64 do software.

\section{Resultados e Discussão}

\subsection{Convergência de Parâmetros}

O algoritmo utilizado neste trabalho foi o mesmo apresentado por Fernandes et al. (2017). Entretanto, antes de começar o processo de otimização pretendido, foram realizados testes de convergência dos parâmetros a fim de testá-los e verificar quais melhor se encaixavam no objetivo a ser alcançado. Esses testes foram feitos executando o algoritmo com diversos valores dentro de um intervalo para cada parâmetro enquanto os demais permaneciam constantes e analisando o valor final da função objetivo. O menor valor da função objetivo ditava qual o melhor parâmetro dentro daquele intervalo.

Os parâmetros analisados foram os seguintes: NP (número de indivíduos ou população), Max Generation (número de iterações ou gerações), $\alpha$ (fator de aleatoriedade), $\beta_{0}$ (fator de atratividade) e Semente.

\subsubsection{População}

Para encontrar o valor ótimo população no processo, foi utilizado um intervalo entre 10 e 400 vagalumes. Já que a oscilação da função objetivo atingiu amplitudes muito altas, o eixo correspondente a ela precisou ser representado em uma escala logarítmica. Para este intervalo, o gráfico representado na partir da Figura 3 permite perceber que o ótimo global se encontra torno de 300 indivíduos.

Figura 3: Comportamento da Função Objetivo versus População.

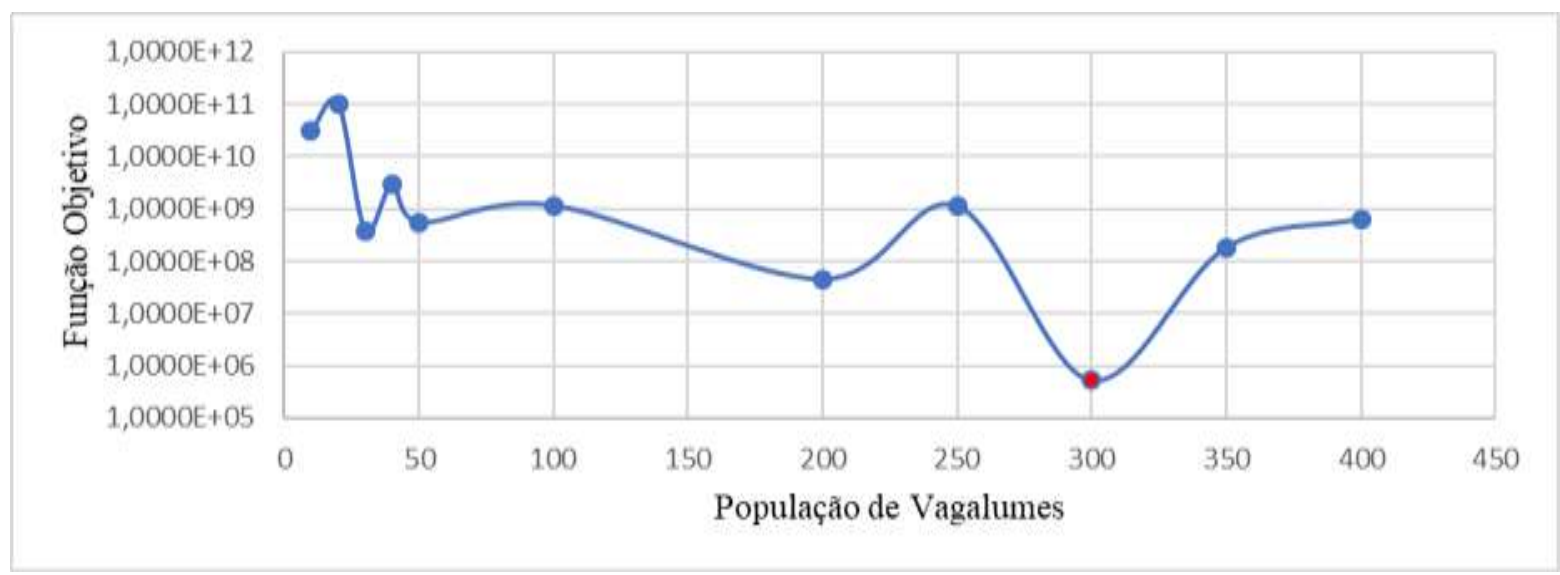

Fonte: Autores, 2022.

\subsubsection{Número de Gerações}


Para encontrar o valor ótimo do número de gerações no processo, foi utilizado um intervalo entre 10 e 10000 repetições. Neste caso, tanto a função objetivo quanto o número de gerações obtiveram oscilações muito altas, então os dois eixos do gráfico correspondente precisaram ser representados por meio de escalas logarítmicas.

Nota-se a partir do gráfico representado na Figura 4 que o valor ótimo para o intervalo utilizado se encontra próximo às 5000 iterações. Porém, já que a diferença de ordem de grandeza da medida da função objetivo entre 500 e 5000 iterações foi relativamente baixa, utilizar-se-á neste trabalho o primeiro valor. Outro motivo para tal escolha, além do já apresentado, é o fato de que a diferença no tempo do processo otimizatório foi exponencialmente maior para o segundo valor.

Figura 4: Comportamento da Função Objetivo versus Número de Gerações.

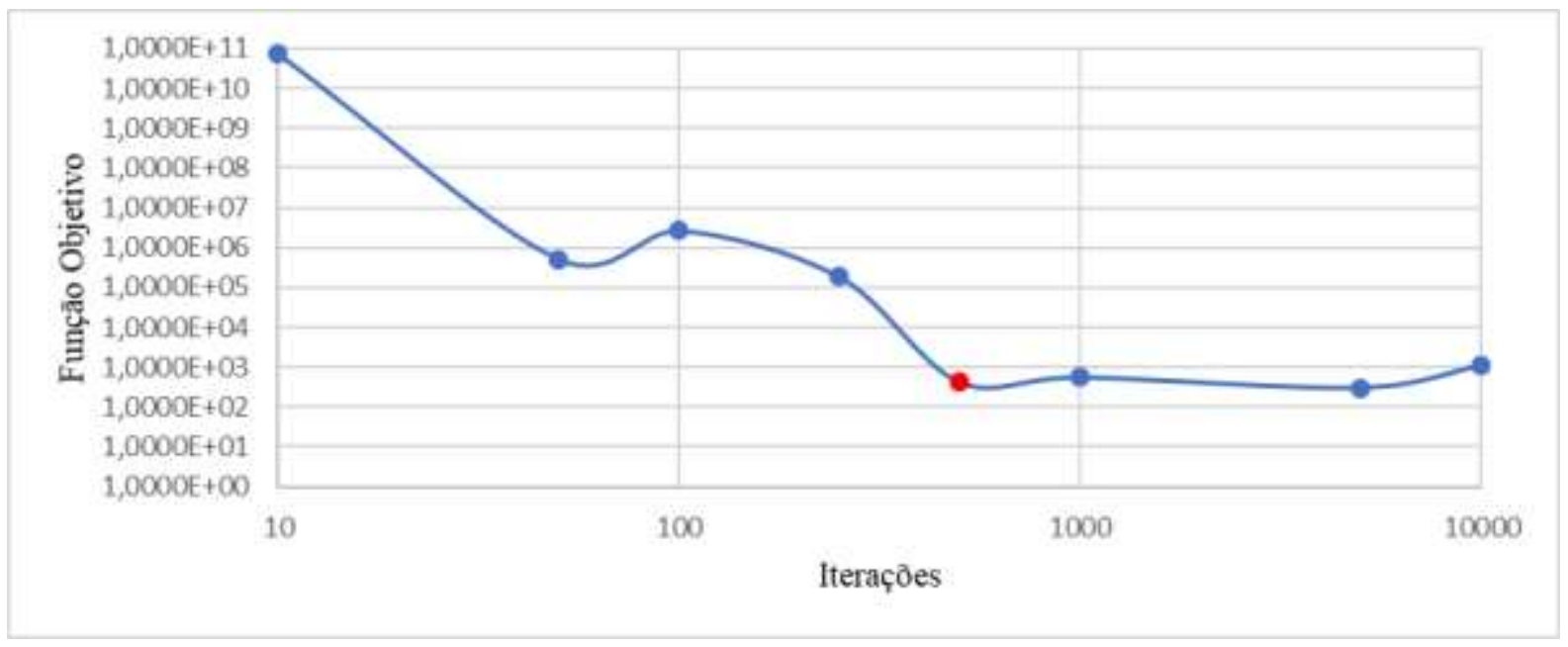

Fonte: Autores (2022).

\subsubsection{Fator de Aleatoriedade}

O parâmetro $\alpha$ representa a movimentação dos vagalumes no processo. Para encontrar seu valor ótimo do parâmetro, foi utilizado um intervalo entre 0,2 e 0,8. Mais uma vez, o eixo correspondente à função objetivo precisou ser representado em uma escala logarítmica. Para este intervalo, o gráfico representado na partir da Figura 5 permite perceber que o ótimo global é encontrado com um fator $\alpha$ em torno de 0,5 .

Figura 5: Comportamento da Função Objetivo versus Aleatoriedade.

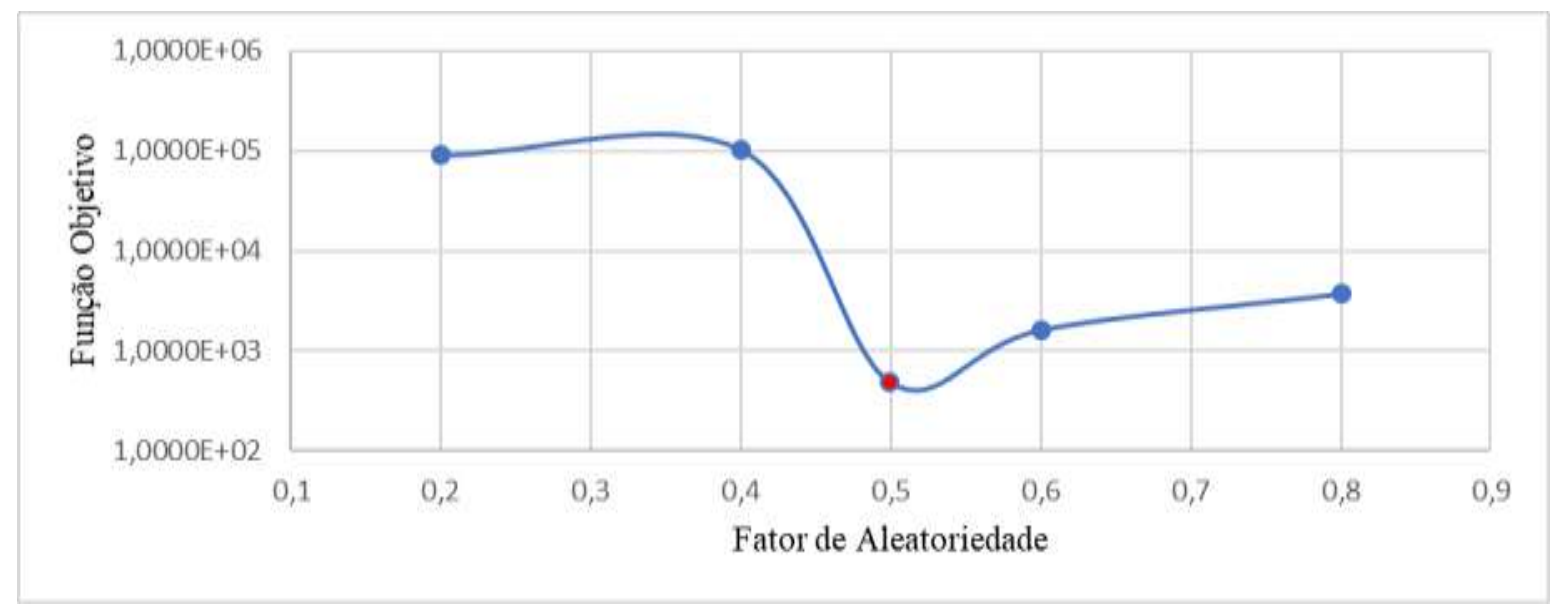

Fonte: Autores (2022). 


\subsubsection{Fator de Atratividade}

O parâmetro $\beta_{0}$ representa a atração entre dois ou mais vagalumes quando a distância tende a zero. Para encontrar seu valor ótimo, foi utilizado um intervalo entre 0,2 e 0,6. Neste caso, Fernandes et al. (2017) deixam claro que o valor mínimo desta variável deve ser 0,2. Como de costume, o eixo correspondente à função objetivo foi representado em uma escala logarítmica. Para este intervalo, o gráfico representado na partir da Figura 6 demonstra que o ótimo global é encontrado com um fator $\beta_{0}$ em torno do valor mínimo de 0,2 .

Figura 6: Comportamento da Função Objetivo versus Atratividade.

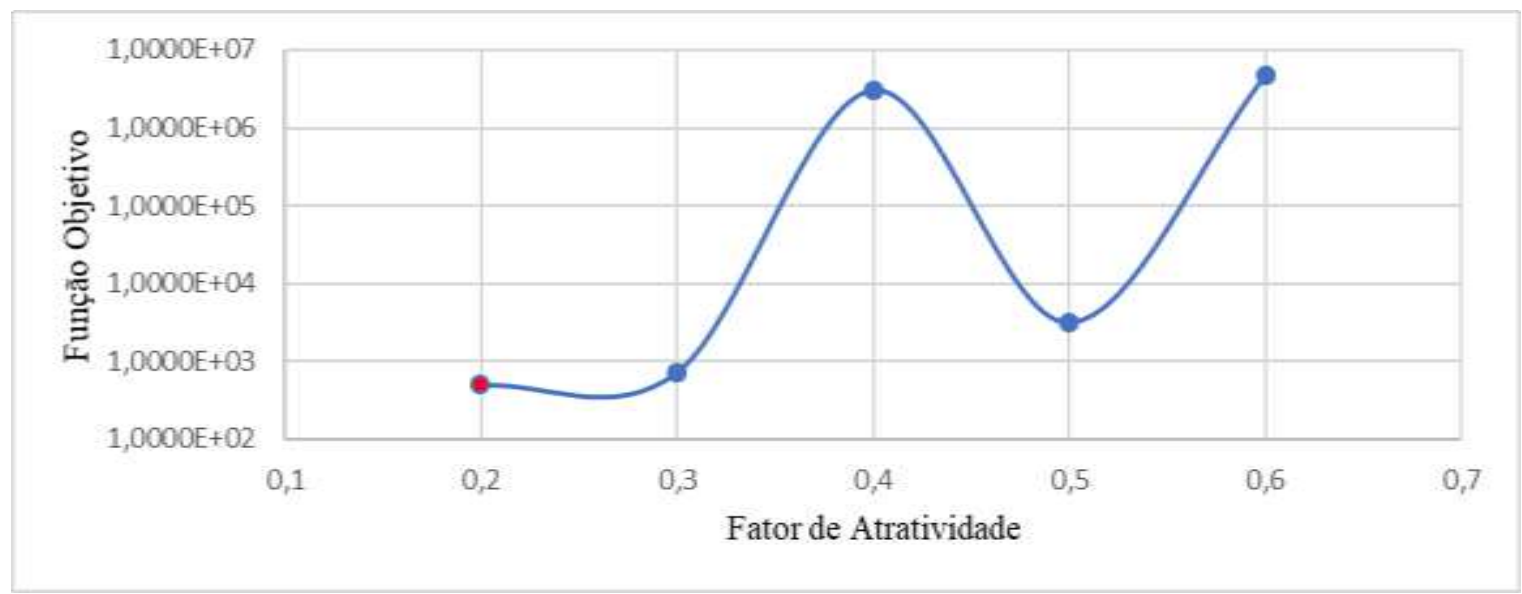

Fonte: Autores (2022).

\subsubsection{Semente}

Semente é o parâmetro em que se estabelece o início do processamento da construção de um número randômico. Seu valor apresentava inconsistência entre o artigo e o algoritmo base para esse trabalho. No primeiro, o valor que constava era de 8 , no segundo, de zero. Por essa razão, o intervalo utilizado para encontrar o valor ótimo deste parâmetro foi entre 0 e 8 . Ao fim dos testes, constatou-se que o valor ótimo era o constante no algoritmo, zero, como representado na Figura 7.

Figura 7: Comportamento da Função Objetivo versus Sementes. 
Research, Society and Development, v. 11, n. 2, e36611225851, 2022

(CC BY 4.0) | ISSN 2525-3409 | DOI: http://dx.doi.org/10.33448/rsd-v11i2.25851

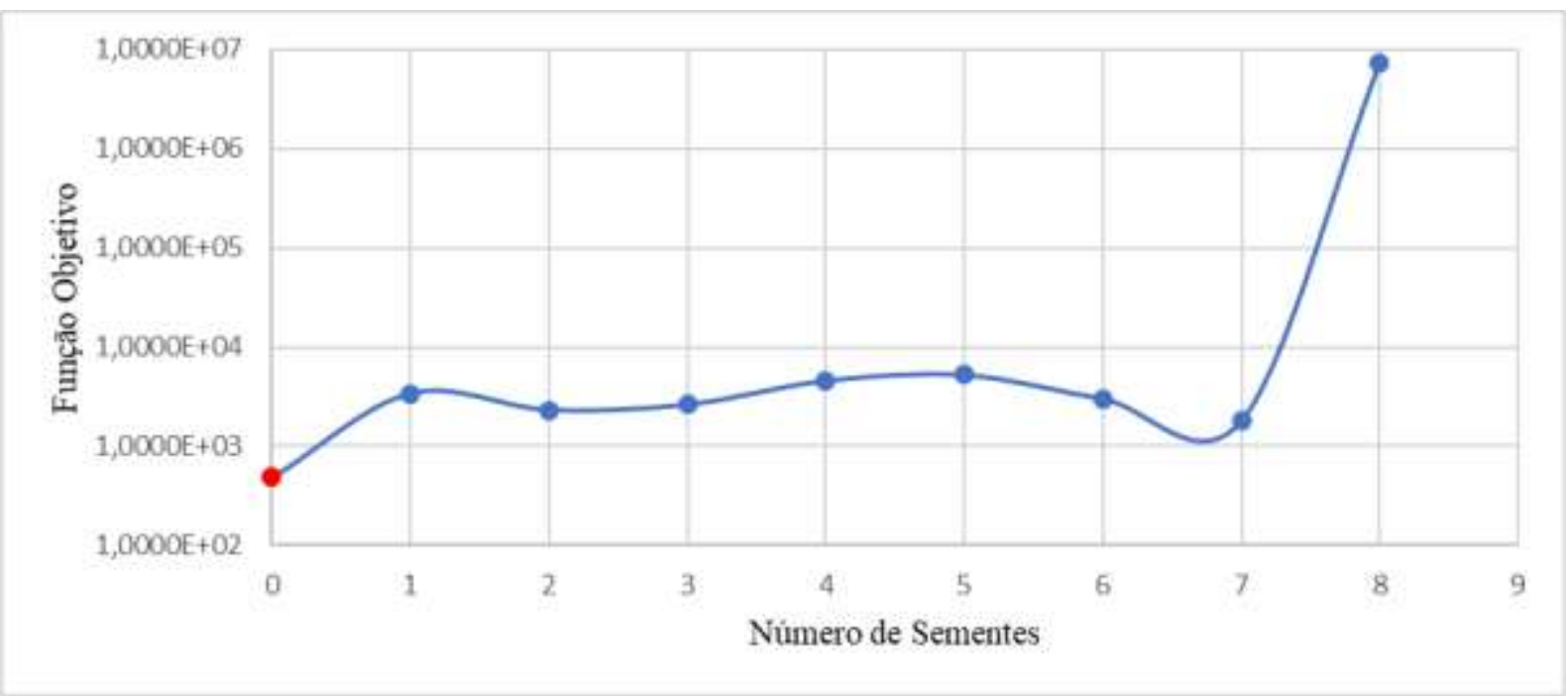

Fonte: Autores (2022).

\subsection{Exemplos de Análise de Resultados}

Com os parâmetros do algoritmo aferidos e estabelecidos, partiu-se para os exemplos. Foram analisadas três vigas com condições de apoio e carregamento distintos. Suas representações esquemáticas e obtenções de máximo momento solicitante foram realizadas através do Ftool®, ferramenta bastante conhecida por alunos que estão iniciando seu contato com estruturas.

\subsubsection{Exemplo 01}

Para o primeiro exemplo, optou-se por uma viga bi-engastada com 4 metros de comprimento, um carregamento distribuído por toda a sua extensão de $315 \mathrm{kN} / \mathrm{m}$ e largura da alma com $20 \mathrm{~cm}$. Sua representação esquemática e momento máximo solicitante encontram-se nas Figuras 8 e 9. Vale ressaltar que, assim como preconiza a NBR 6118 (ABNT, 2007), o máximo momento solicitante sofre ainda uma majoração por um fator $\gamma \mathrm{c}$ de valor 1,4 , dando origem ao máximo momento de projeto, comumente nomeado como Md.

Figura 8: Esquematização da viga do exemplo 01.

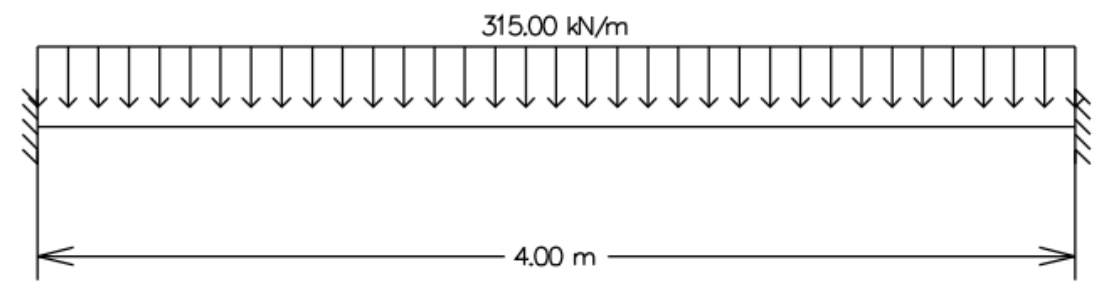

Fonte: Autores (2022).

Figura 9: Momentos solicitantes da viga do exemplo 01. 
Research, Society and Development, v. 11, n. 2, e36611225851, 2022

(CC BY 4.0) | ISSN 2525-3409 | DOI: http://dx.doi.org/10.33448/rsd-v11i2.25851

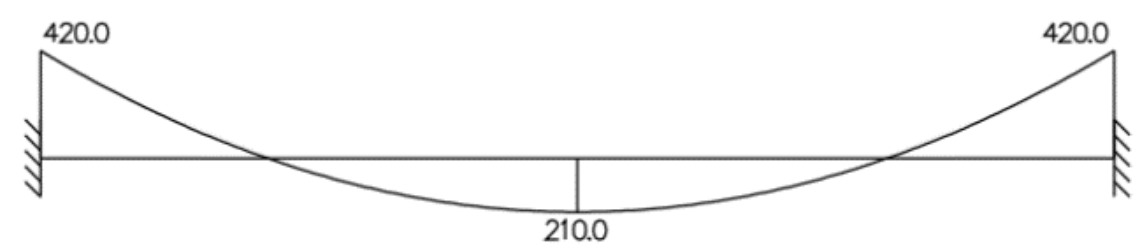

Fonte: Autores (2022).

Para essa viga, o Md atingiu um valor de 588 kN.m. Inserindo essa e as demais variáveis no algoritmo, a saber, os parâmetros encontrados e a largura da alma, foram encontrados os seguintes resultados, expressos nos gráficos das Figuras 10 e 11. 
Figura 10: Minimização da Função Objetivo do Exemplo 01.

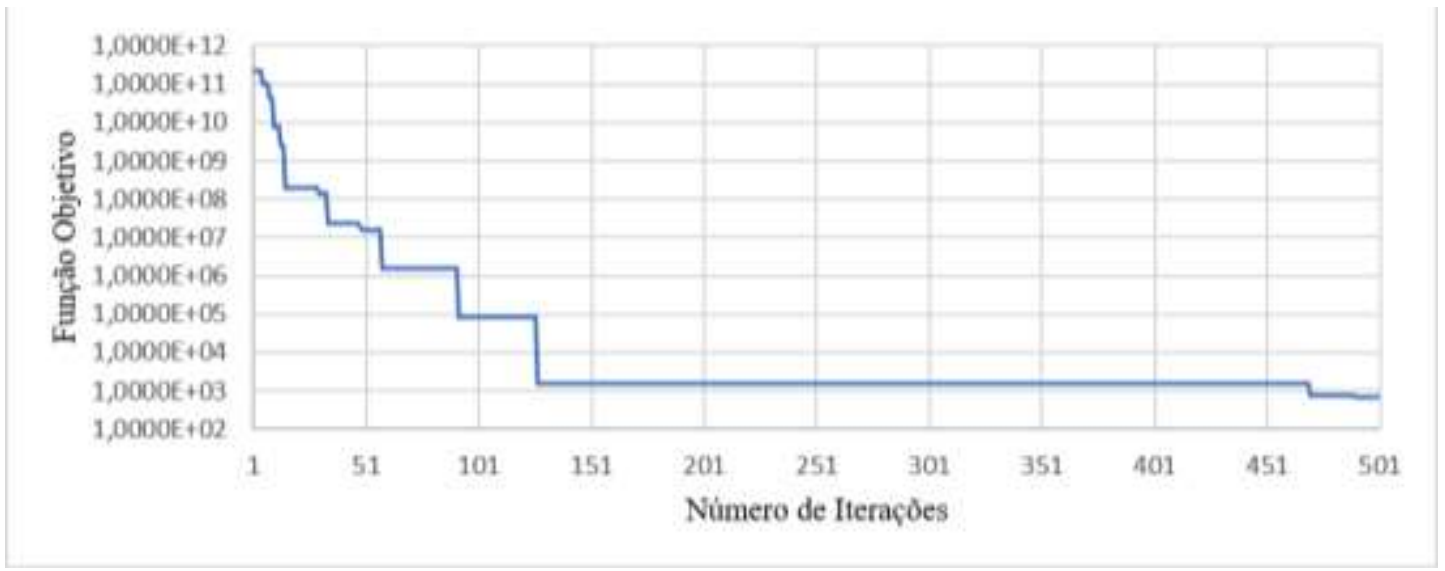

Fonte: Autores (2022).

É possível notar a partir da análise do gráfico anterior que, apesar de terem sido realizadas 500 iterações, todas necessárias para encontrar o valor ótimo, a convergência satisfatória começou a ser apresentada por volta da $130^{a}$ rodada. Esse fato demonstra a potencialidade e robustez do método utilizado.

Figura 11: Otimização Estrutural do Exemplo 01.

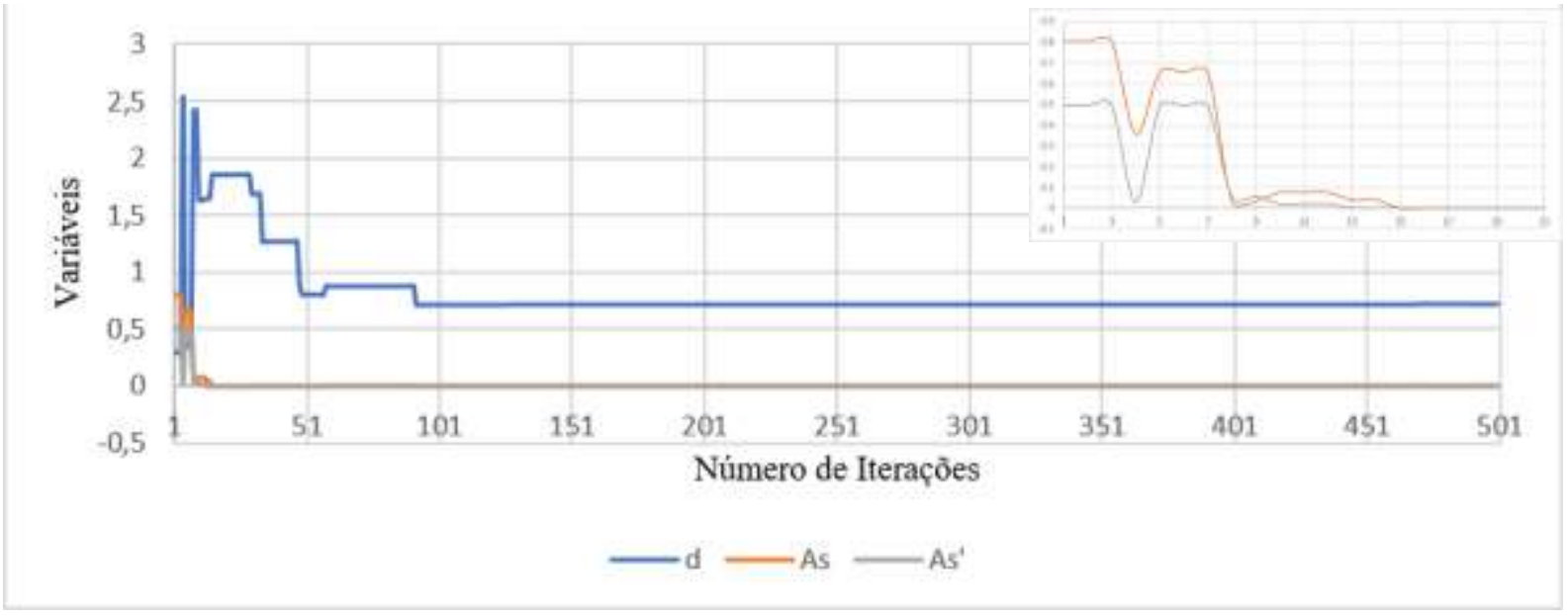

Fonte: Autores (2022).

O gráfico representativo da otimização em si permite aferir que os valores da armadura convergiram muito mais rápido que o valor da altura útil da viga. Tão mais rápido que foi necessário adicionar um gráfico secundário no canto superior direito do gráfico principal. Em tal gráfico, foi excluída a variável d para que fosse possível visualizar como se deu a convergência de As e As'. Essa característica e representação irá se repetir nos demais exemplos a serem apresentado a seguir.

Os valores otimizados das variáveis para esse exemplo foram os seguintes:

$$
\begin{aligned}
& d=0,719968 \mathrm{~m} \\
& A s=0,002518 \mathrm{~m}^{2} \\
& A s^{g}=0 \mathrm{~m}^{2}
\end{aligned}
$$


Inserindo esses valores na função custo, foi obtido um valor de $\mathrm{R} \$ 314,10$ reais/metro. É importante frisar que já que o valor da armadura trabalhando à compressão (a saber, a superior) foi zero, será necessária apenas uma armadura de portaestribo. Essa característica também se repetirá nos demais exemplos.

\subsubsection{Exemplo 02}

De forma análoga, para o segundo exemplo, optou-se por uma viga livre-engastada com 4 metros de comprimento, um carregamento distribuído por toda a sua extensão de $45 \mathrm{kN} / \mathrm{m}$ e largura da alma com $20 \mathrm{~cm}$. Sua representação esquemática e momento máximo solicitante encontram-se nas Figuras 12 e 13.

Figura 12: Esquematização da viga do exemplo 02.

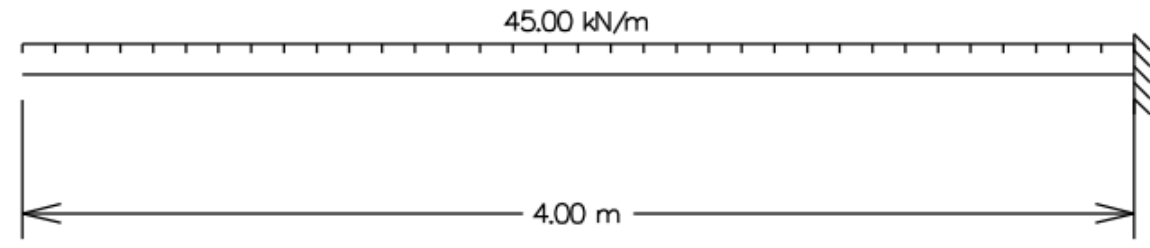

Fonte: Autores (2022).

Figura 13: Momentos solicitantes da viga do exemplo 02.

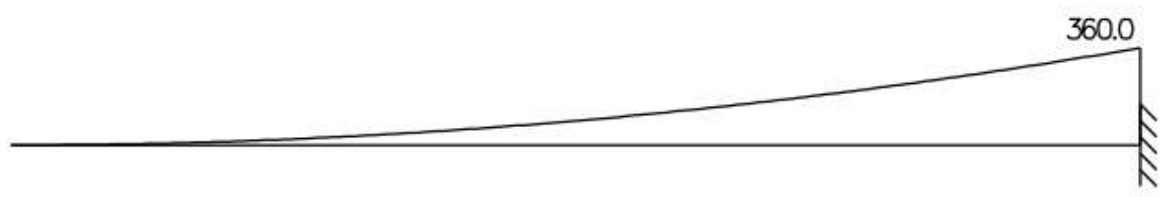

Fonte: Autores (2022).

Para essa viga, o Md atingiu um valor de 504 kN.m. Inserindo essa e as demais variáveis no algoritmo, a saber, os parâmetros encontrados e a largura da alma, foram encontrados os seguintes resultados, expressos nos gráficos das Figuras 14 e 15.

Figura 14: Minimização da Função Objetivo do Exemplo 02.

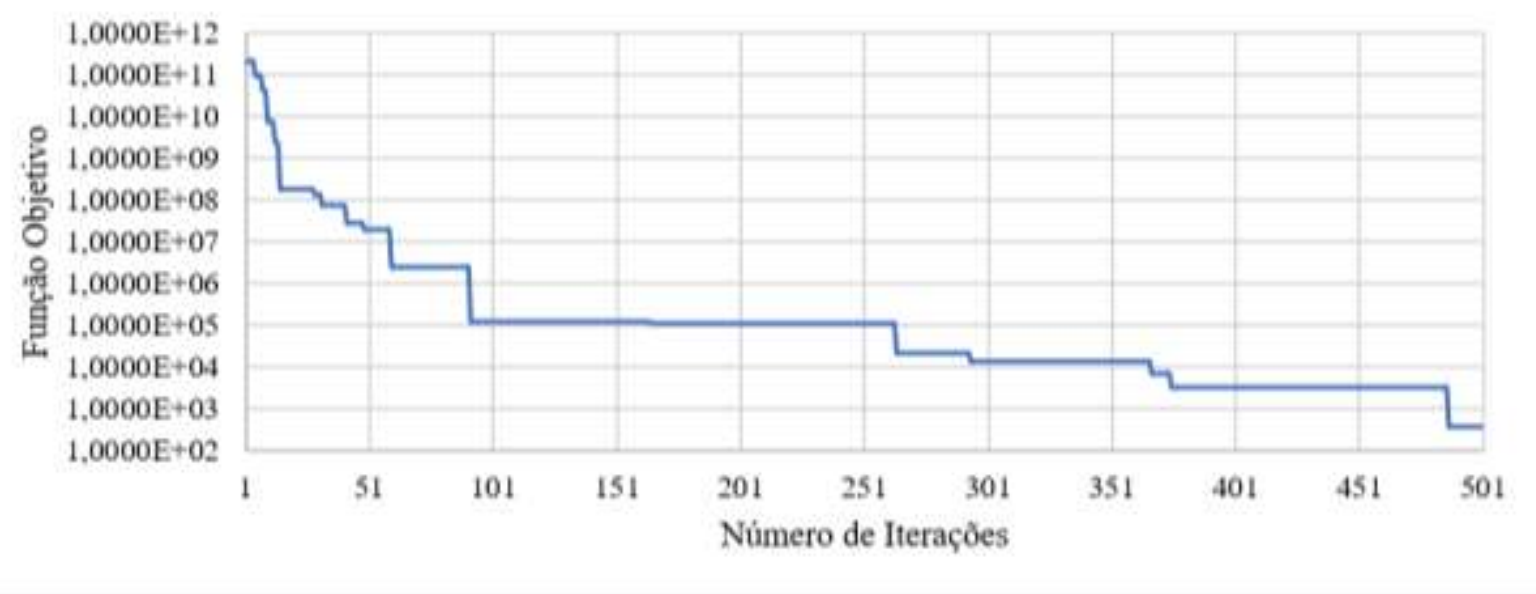

Fonte: Autores (2022). 
Nesse caso, a convergência da função objetivo não se deu de forma tão rápida quanto no exemplo anterior, mas apresentou platôs muito bem definidos por volta da $90^{\mathrm{a}}$ iteração uma queda abrupta a partir da $485^{\mathrm{a}}$ rodada, deixando claro mais uma vez a importância de todas as 500 iterações para o processo.

Figura 15: Otimização Estrutural do Exemplo 02.

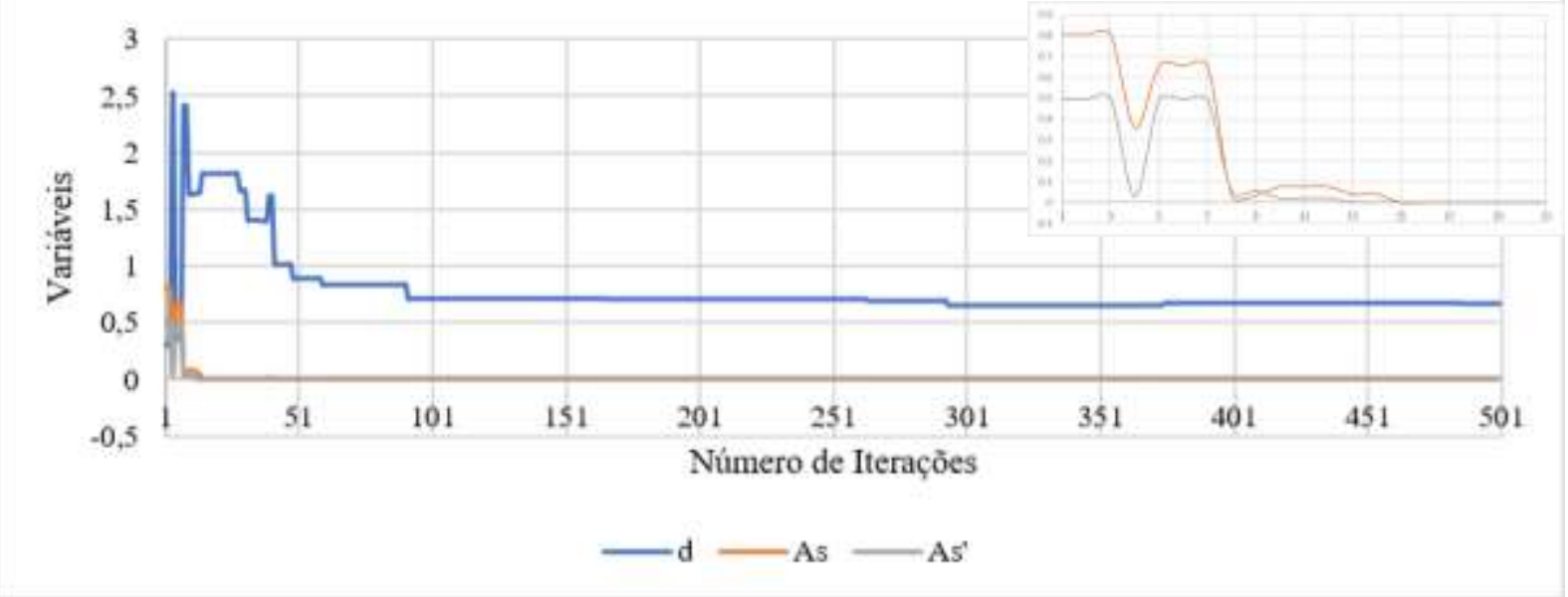

Fonte: Autores (2022).

Os valores otimizados das variáveis para esse exemplo foram os seguintes:

$$
\begin{aligned}
& d=0,66243 \mathrm{~m} \\
& A s=0,002324 \mathrm{~m}^{2} \\
& A s^{s}=0 \mathrm{~m}^{2}
\end{aligned}
$$

Inserindo esses valores na função custo, foi obtido um valor de R\$ 290,57 reais/metro.

\subsubsection{Exemplo 03}

Finalmente, para o terceiro exemplo, optou-se por uma viga livre-livre com 4 metros de comprimento, um carregamento distribuído por toda a sua extensão de $200 \mathrm{kN} / \mathrm{m}$ e largura da alma com $30 \mathrm{~cm}$. Sua representação esquemática e momento máximo solicitante encontram-se nas Figuras 16 e 17.

Figura 16: Esquematização da viga do exemplo 03.

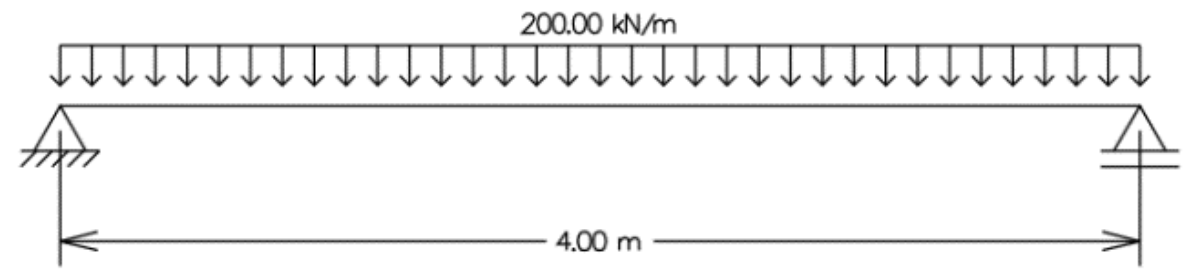

Fonte: Autores (2022). 
Figura 17: Momentos solicitantes da viga do exemplo 03.

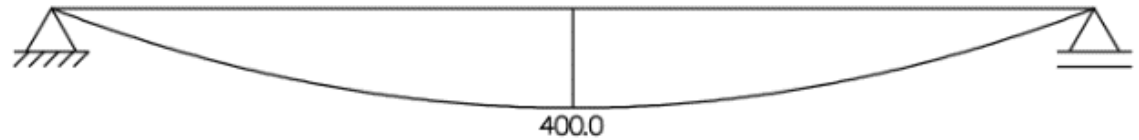

Fonte: Autores (2022).

Para essa viga, o Md atingiu um valor de 560 kN.m. Inserindo essa e as demais variáveis no algoritmo, a saber, os parâmetros encontrados e a largura da alma, foram encontrados os seguintes resultados, expressos nos gráficos das Figuras 18 e 19.

Figura 18: Minimização da Função Objetivo do Exemplo 03.

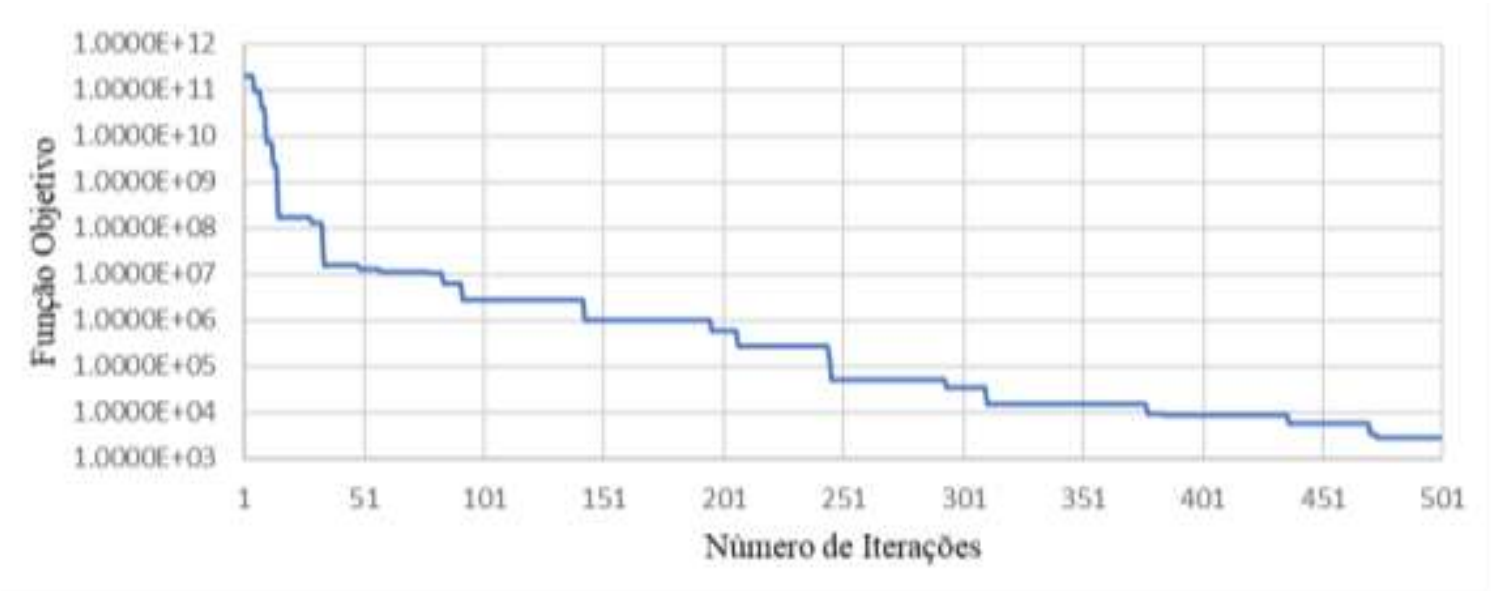

Fonte: Autores (2022).

Dentre todos os exemplos, o terceiro foi o que apresentou uma convergência da função objetivo mais suave, inexistindo trechos muito extensos de constância de valores. Esse exemplo foi o que melhor representou a importância de se utilizar o parâmetro Número de Gerações com o valor de 500 para o objetivo desse trabalho.

Figura 19: Otimização Estrutural do Exemplo 03.

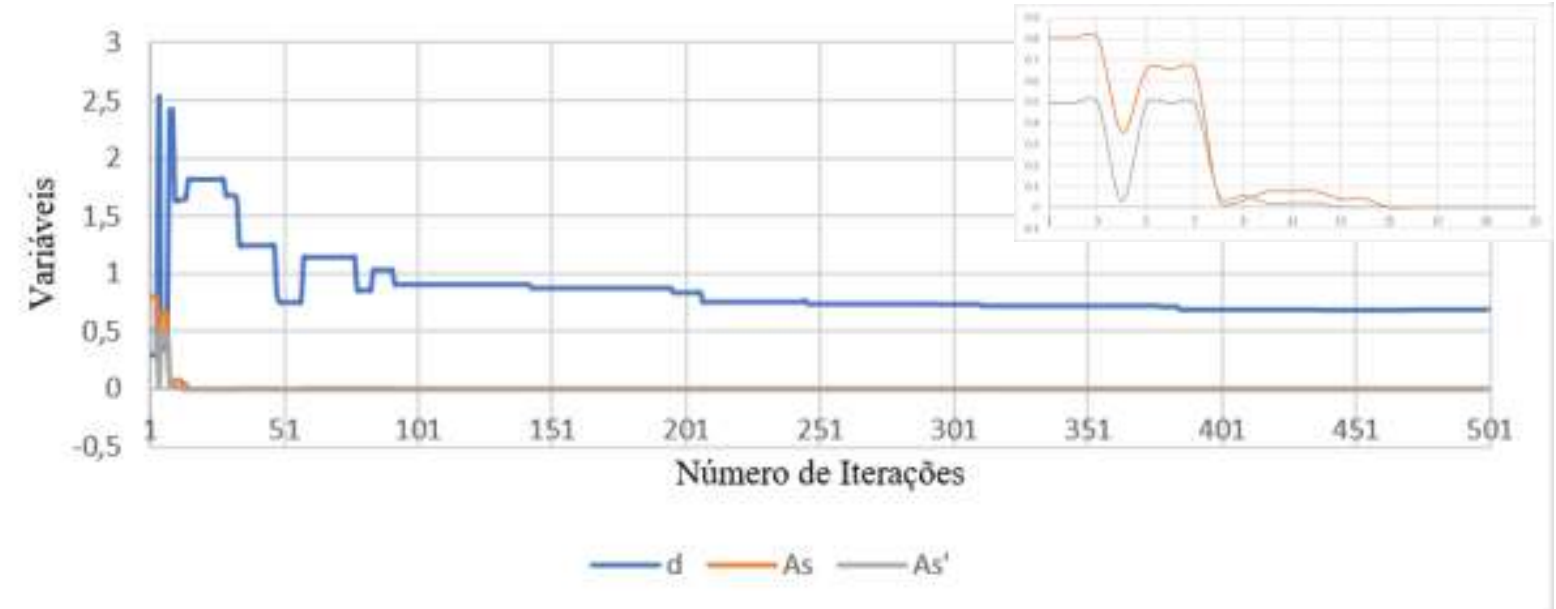

Fonte: Autores (2022). 
Os valores otimizados das variáveis para esse exemplo foram os seguintes:

$$
\begin{aligned}
& d=0,689943 \mathrm{~m} \\
& A s=0,002422 \mathrm{~m}^{2} \\
& A s^{0}=0 \mathrm{~m}^{2}
\end{aligned}
$$

Inserindo esses valores na função custo, foi obtido um valor de $\mathrm{R} \$ 302,23$ reais/metro.

\section{Conclusão}

A partir dos resultados para os problemas apresentados, foi possível perceber a potencialidade e a robustez do algoritmo e do método Colônia de Vagalumes. Esses predicados ficaram evidentes por causa da velocidade com a qual a convergência aproximada foi alcançada em cada um dos exemplos utilizados, apresentando valores muito próximos do valor ótimo com relativa rapidez.

É importante ressaltar que a eficiência do método foi potencializada pela análise de convergência de parâmetros realizada antes de serem rodados os exemplos. Durante a verificação, cada um dos indicadores foi arbitrado enquanto os demais permaneciam constantes em valores aleatórios. Ao se utilizar o algoritmo com todos os fatores escolhidos mediante observação, foi possível alcançar maior proficuidade. Utilizando os valores ótimos para cada parâmetro, o próprio algoritmo funcionou de forma otimizada.

A utilização dessa ferramenta para o cálculo de elementos estruturais de vigas abre precedente para a sua utilização na otimização de vários outros elementos estruturais como pilares, lajes, escadas, reservatórios, entre outros, bastando para isso, a adequação das sub-rotinas do algoritmo.

De forma geral, por fatores já apresentados anteriormente, o uso da otimização na Engenharia Civil é altamente relevante. Porém, essa relevância fica mais evidente em casos de maior escala como otimização de elementos de pontes ou edifícios de maior dimensão. Nesses casos, é possível alcançar valores realmente econômicos. Com as adaptações cabíveis, o algoritmo utilizado nesse trabalho pode ser utilizado, também, nesses casos.

Apontam-se como sugestões para trabalhos futuros a inserção de sub-rotinas e restrições no algoritmo que permitam sua utilização em outros elementos estruturais, a saber, pilares, lajes, reservatórios, entre outros. Seria interessante também a introdução de sub-rotinas e restrições que permitam sua utilização em elementos estruturais pertinentes a outros materiais como estruturas metálicas e de madeira. Por fim, para reduzir o esforço braçal, seria pertinente pôr uma sub-rotina que permita o pós-processamento impresso das informações, para que não seja preciso investir tanto tempo na plotagem de gráficos manualmente.

\section{Referências}

Alves, F. E. (2016). Biomimética: a ciência inspirada no design inteligente da natureza. Raciocínio Cristão. https://www.raciociniocristao.com.br/2016/04/biomimetica-ciencia-design-inteligente.

Arroyo, J. E. C. (2002). Heurísticas e Metaheurísticas para Otimização Combinatória Multiobjetivo. Tese de doutorado. Faculdade de Engenharia Elétrica e de Computação da Universidade Estadual de Campinas - UNICAMP, 200-255.

Associação Brasileira De Normas Técnicas. (2007). ABNT NBR 6118: Projeto de estruturas de concreto - procedimento. Abnt.

Barbosa, C. E. M. (2017). Algoritmos Bioinspirados para Solução de Problemas de Otimização. Tese de Mestrado. Universidade Federal de Pernambuco, 2017.

CBIC. (2020). Após cinco anos negativos, construção civil cresce 1,6\% em 2019. CBIC - Câmara Brasileira Da Indústria Da Construção. https://cbic.org.br/apos-cinco-anos-negativos-construcao-civil-cresce-16-em-2019/. 
Research, Society and Development, v. 11, n. 2, e36611225851, 2022

(CC BY 4.0) | ISSN 2525-3409 | DOI: http://dx.doi.org/10.33448/rsd-v11i2.25851

CBIC. (2021). Sob alta nos preços de insumos e desabastecimento, lançamentos de imóveis caem 17,8\% em um ano no Brasil. CBIC - Câmara Brasileira da Indústria da Construção. <https://cbic.org.br/sob-alta-nos-precos-de-insumos-e-desabastecimento-lancamentos-de-imoveis-caem-178-em-um-ano-no-brasil/> .

Cirino, R. L., Knupp, D. C., \& Neto, A. J. S. (2012) Aplicação do algoritmo de colônia de vagalumes com aprendizado baseado na oposição em um problema inverso de transferência radiativa. XXXIV Congresso de matemática aplicada e computacional, p 1309-1315.

Estrela, C. (2018). Metodologia Científica: Ciência, Ensino, Pesquisa. Editora Artes Médicas.

Fernandes, C. M., Melo, P. H. P., \& Pereira, R. R. (2017). Otimização estrutural de vigas de concreto armado submetidas à flexão simples. In: Tecnologias em pesquisa: engenharias. São Paulo: Blucher, p. 317 -332.

Fister, I., Fister, I., Yang, X.-S., \& Brest, J. (2013). A comprehensive review of firefly algorithms. Swarm and Evolutionary Computation, 13, 34-46. https://doi.org/10.1016/j.swevo.2013.06.001

Lobato, F. S (2016). Guia de Estudos: Algoritmo de Colônia de Vagalumes. Catalão: UFG/PPGMO, p 1-8.

Lopez, R. H., \& Miguel, L. F. (2013) Introdução a otimização estrutural. Florianópolis: UFSC/PPGEC, 2013. 7 p. http://ppgec.posgrad.ufsc.br/files/2013/05/Topicos_Pesquisa_UFSC-timiza\%C3\%A7\%C3\%A3o.pdf.

Malagoli, J. A. (2016). Otimização multiobjetivo aplicada aos motores de indução validada via elementos finitos. Tese de Doutorado. Universidade Federal de Uberlândia, p 1-150.

Moreira, F. R. (2015) Otimização robusta multiobjetivo para o projeto de sistemas de engenharia. Tese de doutorado. Universidade Federal de Uberlândia.

Olivieri, B. P. (2004). Otimização do projeto de pontes protendidas pré-moldadas pelo método dos algoritmos genéticos. Tese de Mestrado. Universidade Federal do Rio de Janeiro.

Örkcü, H. H., Özsoy, V. S., Aksoy, E., \& Dogan, M. I. (2015). Estimating the parameters of 3-p Weibull distribution using particle swarm optimization: A comprehensive experimental comparison. Applied Mathematics and Computation, 268, 201-226

ORSE. (2021). Orçamento de Obras de Sergipe, 2021. http://orse.cehop.se.gov.br/servicosargumento.asp.

Pereira, A. S., Shitsuka, D. M., Parreira, F. J., \& Shitsuka, R. (2018). Metodologia da pesquisa científica. UFSM. https://repositorio.ufsm.br/bitstream/handle/1/1582 4/Lic_Computacao_Metodologia\%20PesquisaCientifica.pdf?sequence=1.

Rastgou, A., \& Moshtagh, J. (2016). Aplicação do algoritmo do firefly para o planejamento da expansão da transmissão em vários estágios com considerações de adequação e segurança em ambientes desregulamentados. Appl. Soft Comput., 41, 373-389.

Rebouças, R. S. (2016). Problema do caixeiro viajante com coleta de prêmios e janelas de tempo. Campinas, SP.

Remes, C. L., Sebem, R., \& Cavalca, M. S. M. (2014). Algoritmos bio-inspirados aplicados ao ajuste de um regulador linear quadrático. XX Congresso Brasileiro de Automática.

Silva, F. E. C. (2015). Otimização dimensional, de forma e topológica de estruturas treliçadas utilizando um algoritmo híbrido. Tese de Mestrado. Universidade Federal do Paraná.

Yang, X-S. (2008). Nature-inspired metaheuristic algorithms. Luniver press.

Yang, X-S. (2010). Nature-inspired metaheuristic algorithms, (2a ed.), Luniver press. 